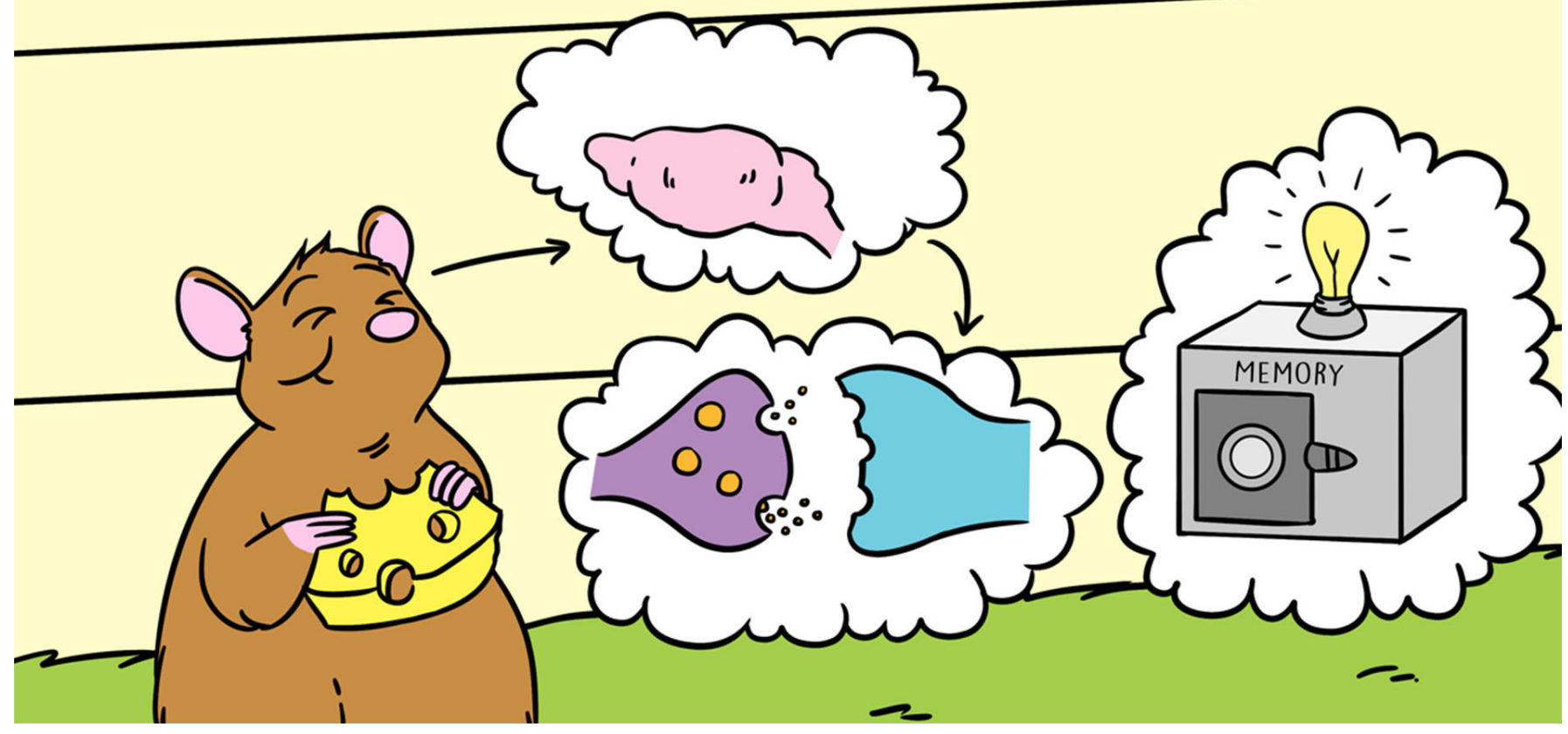

\title{
WHAT ARE ENDOCANNABINOIDS? WHAT DO THEY DO IN THE BRAIN?
}

\section{Rajamani Selvam $^{1 *}$ and Vinita Bharat ${ }^{2}$ \\ ${ }^{1}$ Center for Drug Evaluation and Research, U.S. Food and Drug Administration, Silver Spring, MD, United States \\ ${ }^{2}$ Department of Neurosurgery, Stanford University, Stanford, CA, United States}

YOUNG REVIEWER:

RAFE

AGE: 15
Our brains create and store memories. Do you know how brain cells communicate with each other to store memories? Each brain cell (also called a neuron) talks to other neurons in the brain. These neurons release chemicals called neurotransmitters that enable the brain cells to communicate and help in storing the memory. We were specifically interested in understanding how a growth factor called brain-derived neurotrophic factor (BDNF) facilitates the communication between neurons in the brain region, hippocampus, as memories are formed and stored here. We found that BDNF interacts with endocannabinoids, which are components of marijuana, to facilitate communication between cells in the brain.

Imagine driving along scenic roads, surrounded by fall colors, or eating your favorite ice cream as it drips down the sides of the cone on a hot day! Did your mind go back to the time when you experienced 
HIPPOCAMPUS

A brain region that resembles "sea-horse" like shape, and hence the name "hippocampus."

\section{SYNAPTIC CLEFT}

Space at which the release of the signal occurs is called the synaptic cleft either of these examples? What do you think helped you remember these events?

It is your memory! The brain has several specialized regions that perform different tasks, such as walking, talking, or hearing. The hippocampus is a brain region that is responsible for storing our memories. Just like other brain regions, the hippocampus is made up of brain cells called neurons. Did you know that the neurons talk to each other continuously using different messages that can impact different processes like memory and creativity? Let us learn about how these neurons communicate and what molecules or signals can influence this neuronal communication.

\section{NEURONS USE CHEMICALS, CALLED NEUROTRANSMITTERS, TO TALK TO EACH OTHER}

Neurons can send, process, and receive information from other neurons through electrical and chemical signals. Communication between neurons happens through structures called synapses. Synapses are the areas where two neurons meet. For any communication to happen in synapses, we need a signal and a neuron on either side of the synapse. One of these cells is called the pre-synaptic cell, and this is the cell that sends the signal. The cell on the other side of the synapse, the one that receives the signal, is called the post-synaptic cell (Figure 1). The neurons send messages called neurotransmitters. Neurotransmitters are chemical signals that communicate the information and are present inside the pre-synaptic cell or sending cell. Neurotransmitters are located in sphere-like structures called synaptic vesicles, which are kind of like balloons. Balloons are filled with air, while these vesicles are filled with neurotransmitters. When you are ready to pop a balloon, you can prick it with a needle, right?

Similarly, when the signals are ready to be sent, the vesicles open and release the neurotransmitters into the tiny space between the neurons, called the synaptic cleft. Neurotransmitters are attached to the molecule in the post-synaptic cell called receptors. The receptors are present in the post-synaptic cell or receiving cell (Figure 1).

There are lots of different kinds of neurotransmitters, but one neurotransmitter that is of interest to us is gamma-aminobutyric acid or GABA. GABA is an inhibitory neurotransmitter, which can be thought of as the "brakes of the brain," because it slows down brain activity, helping us to sleep and reducing stress and anxiety. If it was not for inhibitory neurotransmitters, the brain would experience too much activity and would not be able to function correctly.

Other kinds of neurotransmitters exist that work a little differently from the way we have described. These unconventional neurotransmitters 


\section{Figure 1}

Neurons talk to each other via synapses. The synapse consists of the pre-synaptic and post-synaptic cell. A Presynaptic cell has vesicles that contain neurotransmitters.

These

neurotransmitters bind to the receptors present in the post-synaptic cell.

\section{RETROGRADE}

\section{MESSENGERS}

The signal is released by the post-synaptic cell or the receiving cell and travels back to the presynaptic cell.

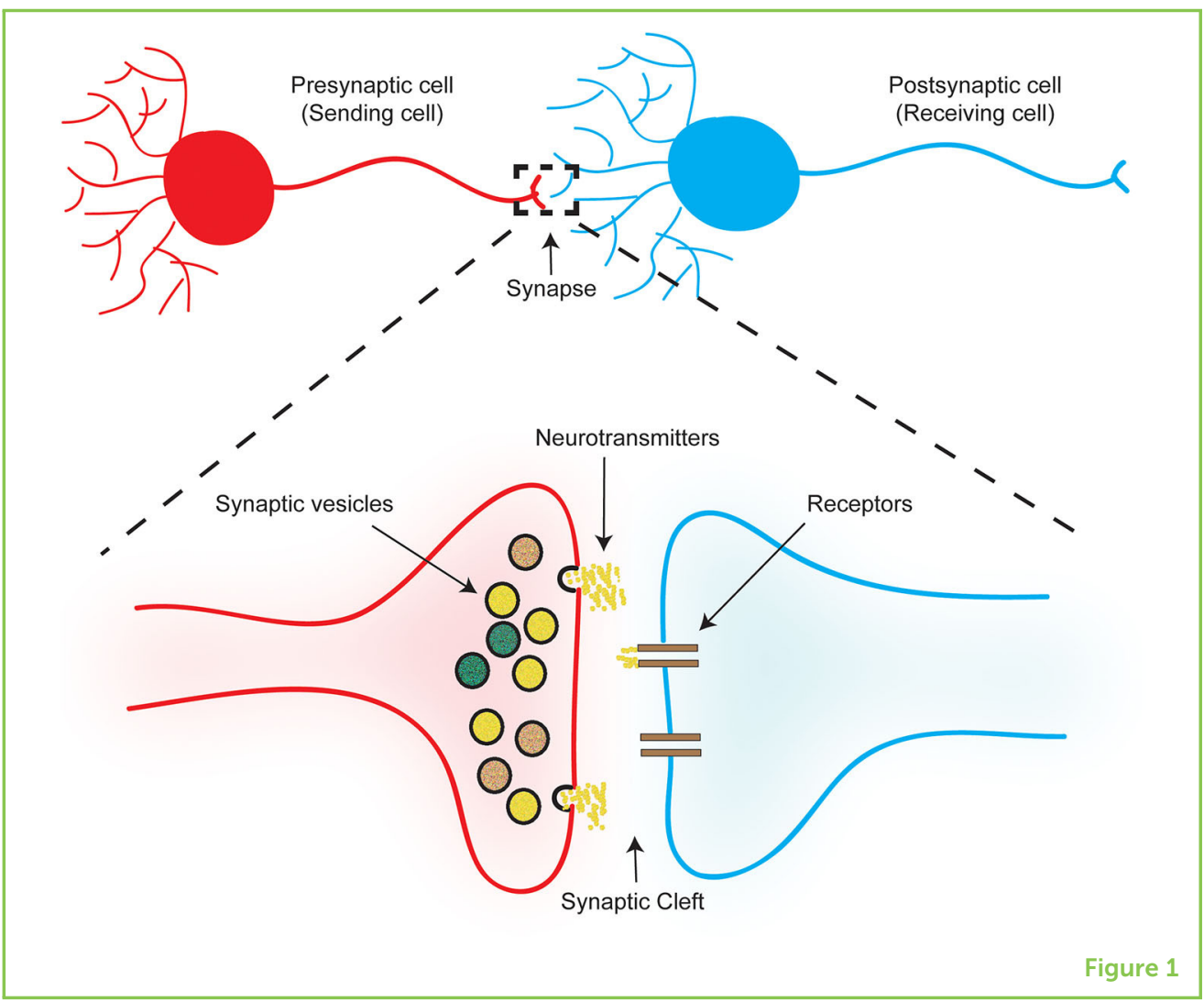

are not stored in synaptic vesicles and can be produced when needed. Some of them carry messages in the reverse direction-from the post-synaptic, receiving cells back to the sending cells. Endocannabinoids are an example of retrograde messengers.

Endocannabinoids (eCBs) are one of the active components present in marijuana. Endocannabinoids are lipid (fat) molecules that have been shown to play a critical role in neuronal communication in the brain [1]. But these chemicals do not just exist in the marijuana plant. Did you know that your brain can naturally produce endocannabinoids? And, these eCBs are produced on demand and bind to their cannabinoid receptors (CB1) to participate in neuronal communication [1].

\section{HOW MIGHT ENDOCANNABINOIDS WORK IN THE BRAIN?}

To explain the role of eCBs, we first have to introduce another molecule, called brain-derived neurotrophic factor (BDNF). BDNF is known to affect communication between neurons. BDNF binds to its receptor, Tropomyosin receptor kinase B (TrkB). Researchers have shown that BDNF can cause a decrease in the release of GABA, thereby interfering with the brain's braking system. In our earlier research, we showed that BDNF binds to TrkB receptors in the post-synaptic 
Figure 2

Slice electrophysiology. The mouse brain was isolated from the animal. Thick sections of the mouse brain were made. We identified the CA1 pyramidal neurons in the slices, using a microscope, and a glass electrode was used to poke a neuron in the defined area. The electrical activity of the neuron was then recorded through the electrode.

\section{CA1 PYRAMIDAL}

\section{NEURONS}

Hippocampus has several sub-regions; CA1 is one among them. CA1 has neurons that resemble a pyramid in shape and referred to as pyramidal neurons.

\section{ELECTROPHYSIOLOGY}

"Electro" refers to electric current, and "physiology" refers to observing the function of an organism.

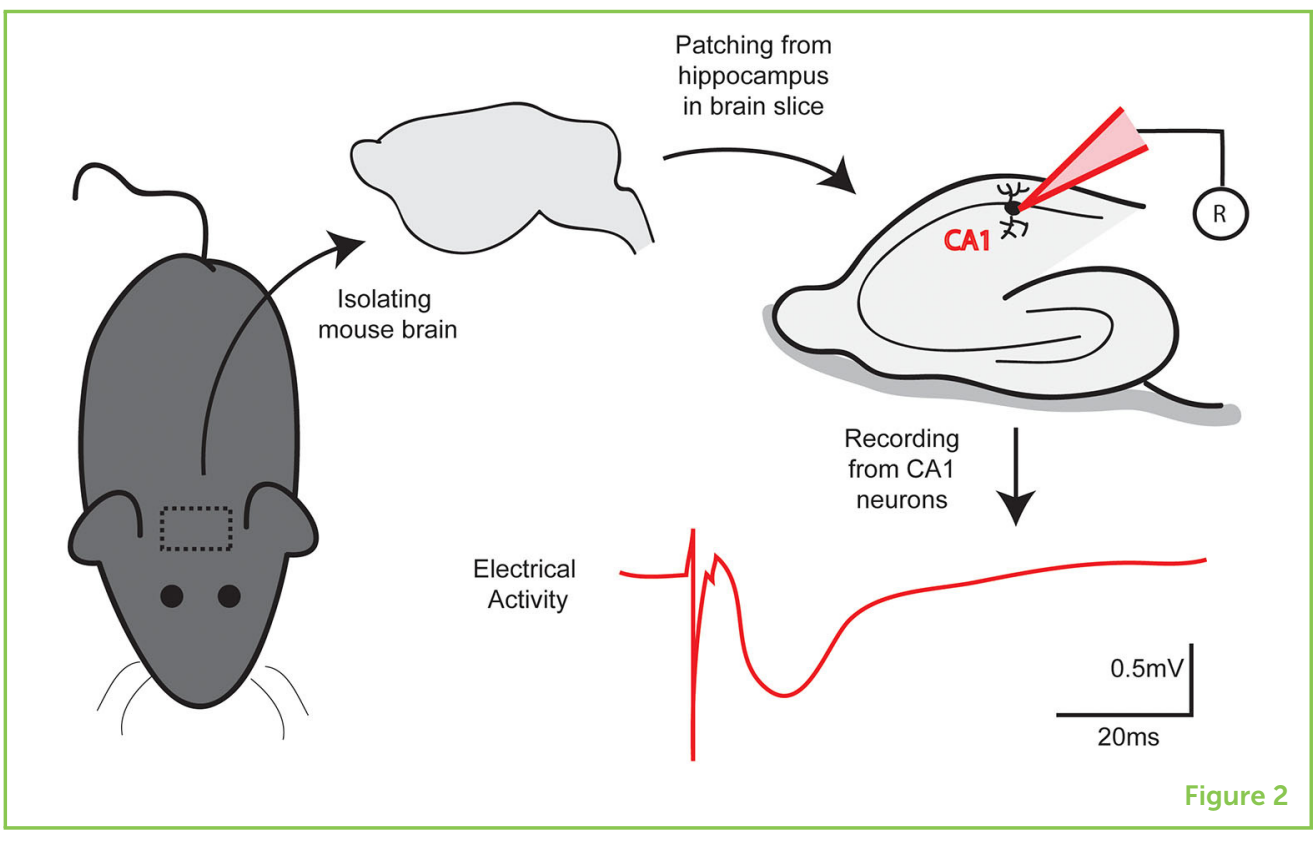

cell (message-receiving cells), and somehow sends a message back to the presynaptic cell (message-sending cells), thus signaling the presynaptic cells to decrease the amount of GABA they are releasing. This is a pretty unusual way for neurons to communicate with each other, so we wanted to understand this process better. Notably, we were interested in whether eCBs play a role in this process as eCBs are retrograde messenger, and the effect of BDNF occurs through a retrograde messenger. We hypothesize that maybe BDNF causes the production of eCBs that further facilitates a decrease in the levels of GABA in the hippocampus.

\section{HOW DID WE TEST OUR HYPOTHESIS ABOUT ENDOCANNABINOIDS?}

To address our questions, we chose to look at a particular type of cells in the hippocampus, called CA1 pyramidal neurons. We chose these cells because a high concentration of BDNF and its receptor TrkB are present in this region. To test our hypothesis, we used a technique called slice electrophysiology to measure the activity of the cells in mice (Figure 2). We sacrificed the mice and dissected their brains, cutting each brain into thick slices [2].

CA1 pyramidal neurons were identified in each slice using a microscope. Then, we poked the CA1 pyramidal neurons with a glass electrode to invoke responses, which helped determine the electrical activity of the neurons. With this setup, we first measured the electrical activity of the cells without any drugs present, which we called the baseline. Then, we treated the neurons with drugs that block BDNF or eCBs receptors to see how these substances changed the electrical activity in the neurons. For instance, adding BDNF or eCBs to the 
Figure 3

Summary of results: BDNF binds to TrkB receptors in the receiving cell that signals a message to produce

endocannabinoids (eCBs). Released eCBs bind to CB1 receptors in the sending cell or presynaptic cell and instructed a decrease in the release of the neurotransmitter, GABA.

\section{2-ARACHIDONOYL-}

\section{GLYCEROL}

\section{A type of} endocannabinoid that is produced by our nervous system on-demand.

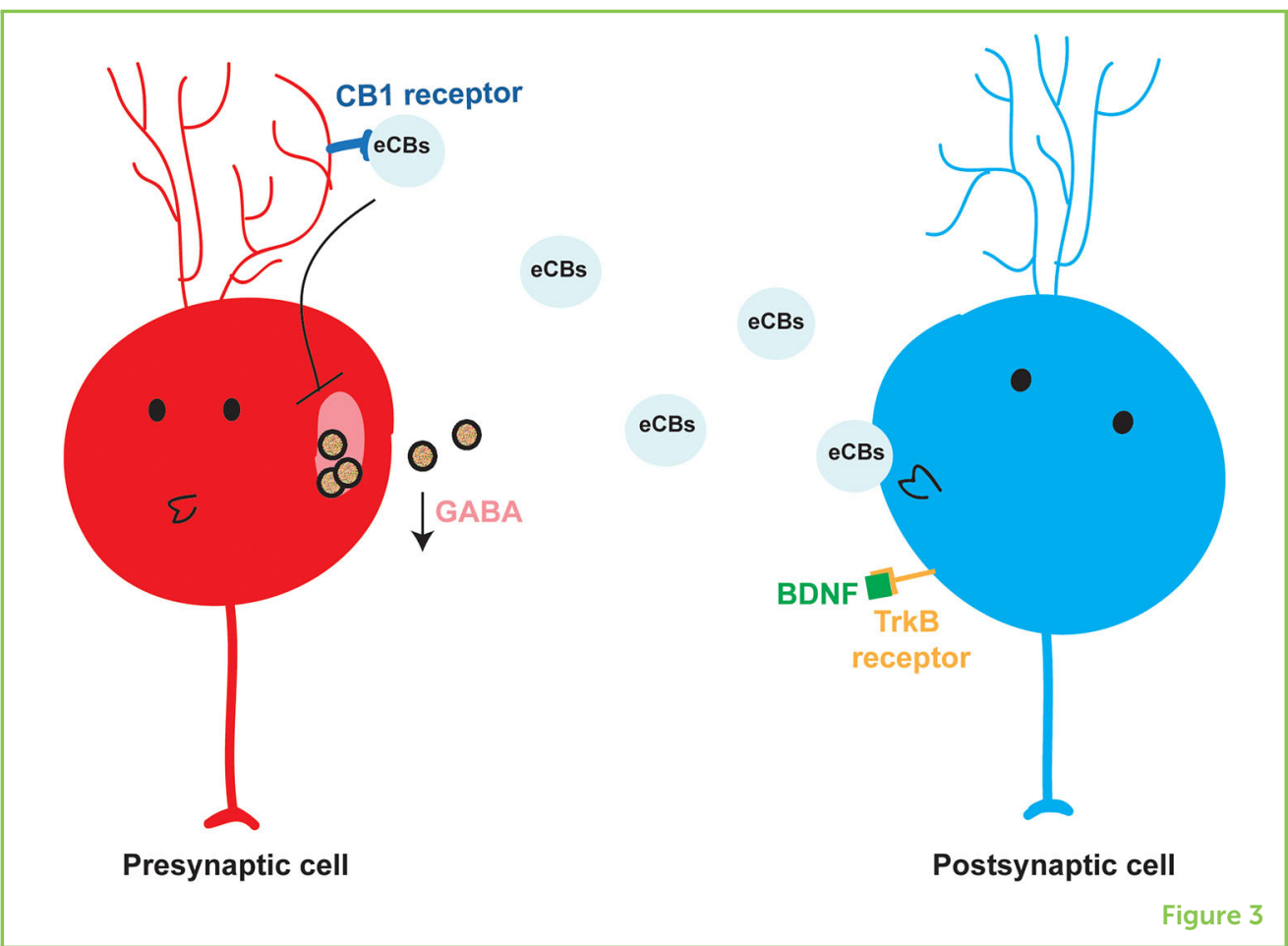

neurons will decrease the electrical response. While blocking BDNF receptors will not cause any decrease in the electrical activity in the neurons.

\section{WHAT DID WE FIND?}

Using the experiments we described, we found that BDNF did, in fact, rely upon endocannabinoids to cause a decrease in the release of GABA from CA1 pyramidal neurons in the hippocampus. In the presence of BDNF, the electrical activity in the neurons was reduced, thereby decreasing the GABA release. However, when we blocked the receptors of $B D N F$, we no longer saw the reduction in GABA release. Similarly, when we blocked the receptors of eCB, we did not see the decline in GABA release indicating that the BDNF indeed instructs the production of eCBs. Among different eCBs that exist in the brain, we identified 2-arachidonoylglycerol as the eCB that is produced by the neurons in this process [3].

To summarize, when BDNF is present, it sends a message from the post-synaptic, receiving cells traveling backward to the presynaptic or sending cell. The message is executed in two steps: (i) BDNF binding to its receptor TrkB and (ii) instructing the release of eCB. The released eCB then travel backwards to the presynaptic cell where it binds to CB1 receptor. The net result of this interaction is the reduction in the release of GABA from the presynaptic cell (Figure 3). 


\section{WHY IS THIS RESEARCH IMPORTANT?}

For decades, researchers have studied the direct effect of a single molecule (and not multiple) and its influence in neuronal communication. In this context, our current research is important as it sheds light on the interactions between different molecules and how it can influence the communication in neurons. Through our work, we have shown that BDNF communicates with cells through endocannabinoids, in a non-traditional way, to decrease GABA release by neurons [3]. As our knowledge on how these molecules influence communication strengthens, we can understand the impact of these factors in various processes like memory formation, storage and retrieval.

\section{AUTHOR CONTRIBUTIONS}

RS wrote the manuscript and VB designed all the figures. RS did this work as part of her Ph.D. thesis at the University of Connecticut Health, Farmington, CT.

\section{ORIGINAL SOURCE ARTICLE}

Selvam, R., Yeh, M. L., and Levine, E. S. 2019. Endogenous cannabinoids mediate the effect of BDNF at CA1 inhibitory synapses in the hippocampus. Synapse 73:e22075. doi: 10.1002/syn.22075

\section{REFERENCES}

1. Lu, H. C., and Mackie, K. 2016. An introduction to the endogenous cannabinoid system. Biol. Psychiatry 79:516-25. doi: 10.1016/j.biopsych.2015.07.028

2. Segev, A., Garcia-Oscos, F., and Kourrich, S. 2016. Whole-cell patch-clamp recordings in brain slices. J. Vis. Exp. 112:e54024. doi: 10.3791/54024

3. Selvam, R., Yeh, M. L., and Levine, E. S. 2019. Endogenous cannabinoids mediate the effect of BDNF at CA1 inhibitory synapses in the hippocampus. Synapse 73:e22075. doi: 10.1002/syn.22075

SUBMITTED: 17 September 2019; ACCEPTED: 11 August 2020; PUBLISHED ONLINE: 15 September 2020.

EDITED BY: Fanli Jia, Seton Hall University, United States

CITATION: Selvam R and Bharat V (2020) What Are Endocannabinoids? What Do They Do in the Brain? Front. Young Minds 8:127. doi: 10.3389/frym.2020.00127

DISCLAIMER: The endocannabinoids can have a positive or negative effect on neuronal communication depending on several factors, such as brain region, brain 


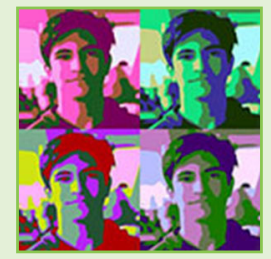

cell type and type of neurotransmitters. Hence it is critical to consider the influence of endocannabinoids in a specific context rather than a generalized context.

CONFLICT OF INTEREST: The authors declare that the research was conducted in the absence of any commercial or financial relationships that could be construed as a potential conflict of interest.

COPYRIGHT @ 2020 Selvam and Bharat. This is an open-access article distributed under the terms of the Creative Commons Attribution License (CC BY). The use, distribution or reproduction in other forums is permitted, provided the original author(s) and the copyright owner(s) are credited and that the original publication in this journal is cited, in accordance with accepted academic practice. No use, distribution or reproduction is permitted which does not comply with these terms.

\section{YOUNG REVIEWER}

\section{RAFE, AGE: 15}

Rafe is currently a sophomore attending The Packer Collegiate Institute. He is passionate about many areas of science and mathematics, and also enjoys playing soccer.

\section{AUTHORS}

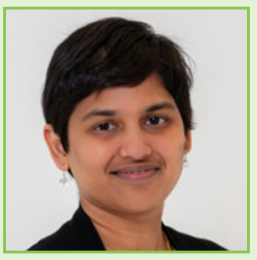

\section{RAJAMANI SELVAM}

Rajamani Selvam received her Ph.D. in Neuroscience. She is pursuing a regulatory research fellowship at the U.S. Food and Drug Administration. She is a science communicator who expresses herself through various mediums as a freelance editor, writer and illustrator. She supports and creates awareness of brain research by participating in hands-on activities and doing science outreach in elementary and high schools. She also mentors students through Freedom Employability Academy, where she provides career guidance. Away from science, she is an artist and enjoys leisure travel. *rajamaniselvamagmail.com

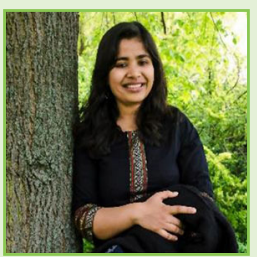

\section{VINITA BHARAT}

Vinita Bharat is a post-doctoral researcher in the Department of Neurosurgery, Stanford University, USA. While she enjoys being a scientist, she has developed an appetite for communicating science to a broader audience. To present science in a fun and easy way, using her sketching pencils and sense of humor, she has started a platform called "Fuzzy Synapse" (http: / / fuzzysynapse.com). Bridging this gap with the illustrations and cartoons is what she loves to do through this platform. She is a fun, enthusiastic, and curious person, passionate about traveling, and she loves celebrations and bringing smiles. 